\title{
Comparative study of efficacy and safety of vaginal misoprostol versus oral misoprostol in induction of labour when used in equal doses
}

\author{
Ambika H. E., Swathi Bhat*, Lepakshi B. G., Savitha C. S.
}

Department of Obstetrics and Gynecology, Shimoga Institute of Medical Sciences, Shimoga, Karnataka, India

Received: 21 July 2017

Accepted: 02 August 2017

*Correspondence:

Dr. Swathi Bhat,

E-mail: swathinandakishore@gmail.com

Copyright: () the author(s), publisher and licensee Medip Academy. This is an open-access article distributed under the terms of the Creative Commons Attribution Non-Commercial License, which permits unrestricted non-commercial use, distribution, and reproduction in any medium, provided the original work is properly cited.

\begin{abstract}
Background: It was a randomized controlled prospective study. A large number of women in their advanced pregnancies often need labour induction for various reasons. This study aims to evaluate a safe, effective and inexpensive mode of medical induction. The purpose of the study is to evaluate the safety and efficacy of vaginal misoprostol versus oral misoprostol in induction of labour when used in equal doses.

Methods: Two hundred patients were included in the study. They were divided into two groups of 100 patients each. One group i.e. Group A received vaginal misoprostol while the other group i.e. Group B received oral misoprostol. The dosage was $50 \mu \mathrm{g}$ every $6^{\text {th }}$ hourly maximum of four doses. The progress of labour in both groups was charted on a partogram. The outcome of pregnancy, maternal and foetal outcomes were statistically analysed.

Results: When compared with respect to age, height, gestational age, indication for induction, there was no difference in either of the groups. The numbers of doses of misoprostol for successful outcome of labour in the vaginal group i.e. $2.25 \pm 0.53$ was lesser than the dosage needed in the oral group i.e. $2.71 \pm 0.60$ (P value M 0.0001). which is highly significant. The induction-delivery interval was also less in the vaginal group compared to the oral group. (12.90 \pm 2.40 hours versus $15 \pm 75$ hours). Only 13 women in the vaginal group needed acceleration with oxytocin in contrast to 17 women in the oral group. The need for caesarean section in women induced with vaginal misoprostol was 12 women in comparison to oral group which was 32 women. No statistically significant difference was seen in neonatal outcome in either of the groups.

Conclusions: When given in equal doses the vaginal administration of misoprostol is more effective in successful induction of labour when compared to oral misoprostol.
\end{abstract}

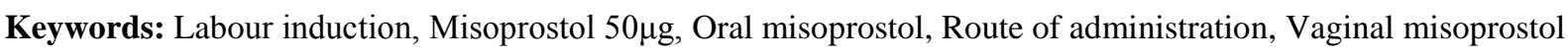

\section{INTRODUCTION}

Induction of labour is defined as the artificial initiation of uterine contractions prior to their spontaneous onset, any time after foetal viability, with or without ruptured membranes by a method that aims at vaginal delivery. ${ }^{1}$

A successful induction depends on the gestational age, favourable Bishops score, parity of the woman, and presence or absence of PROM. ${ }^{2}$ A Bishop score of $\geq 6$ has a favourable outcome where as a score of $\leq 3$ usually ends up with failed induction.

Misoprostol, a prostaglandin $\mathrm{E}_{1}$ analogue (a methyl ester of $\mathrm{PGE}_{1}$ ) which was used primarily for prevention of analgesic associated ulcers of the gastro intestinal tract, is a potent drug for labour induction. It was first used in 1987 for induction of labour in a dead foetus. ${ }^{3,4}$ It is an inexpensive drug which can be administered through the vaginal, oral, sublingual, per rectal routes. ${ }^{5}$ Misoprostol 
can be stored in room temperature, does not need refrigeration and has very minimal systemic side effects.

In this study, the safety and efficacy of oral versus vaginal misoprostol is being evaluated for induction of labour. The dosage used in $50 \mathrm{mcg}$ every 6 hours. Also, the time taken from induction to delivery, need for augmentation of labour, maternal and foetal outcomes in each group is analysed.

\section{METHODS}

This study was conducted in the Department of Obstetrics and Gynaecology, Shivamogga Institute of Medical Sciences, Shivamogga from May 2016 to May 2017.

The study group consisted of 200 women. A written informed consent was obtained from the patients.

\section{Inclusion criteria}

Women considered for the study were primigravida with a single live intrauterine pregnancy with cephalic presentation of 36-41 weeks of gestation. Pelvic assessment was done for all the patients, cephalopelvic disproportion was ruled out. Bishops scoring was done. Foetal well-being was ensured by reactive Non-stress test.

\section{Exclusion criteria}

Any woman with a known or suspected hypersensitivity to prostaglandins, or with a history of previous scared uterus i.e. myomectomy, uterine anomaly was excluded from the study. Women with antenatal pregnancy complications that may require emergency Caesarian Section were also excluded from the study.

A random allocation of the women to Group A i.e. who received misoprostol tablets $50 \mathrm{mcg}$ every 6 hours by vaginal route for 24 hours i.e. maximum 4 doses, or Group B who received similar doses orally was done. Each group had 100 patients.

Bishops score for each patient was assessed. A detailed history and examination was done. The gestational age was estimated based on the last menstrual period and early pregnancy ultrasound scan reports.

Details of age, height, history of the patients, number of doses of misoprostol, induction to delivery interval and mode of delivery was recorded. Maternal or foetal complication if any was documented. Partogram was plotted for all women in labour.

When a patient was in active labour i.e. when patient had 3-4 painful uterine contraction in a 10-minute period each lasting for 30-40 seconds artificial rupture of membranes was done. Following which, misoprostol was stopped and oxytocin infusion was started for augmentation of labour if needed. Progress of labour was plotted on a partogram. Women who were not in active phase of labour were given the next dose of misoprostol as per the schedule.

Women who did not go into active phase of labour at the end of 24 hours were considered to have failed induction. The results were statistically analyzed.

\section{RESULTS}

Out of 200 patients who were randomly assigned to either of the groups, the age, height, gestational age, Bishop's score, indication for induction of labour were comparable. The main indication for induction of labour, namely prolonged pregnancy, Pregnancy induced hypertension, and premature rupture of membranes in either of the groups remained the same.

Table 1: Indication for labour induction.

\begin{tabular}{|lll|}
\hline Indication & Group A & Group B \\
\hline Prolonged pregnancy & 50 & 48 \\
\hline PIH & 35 & 30 \\
\hline PROM & 10 & 9 \\
\hline Others & 5 & 13 \\
\hline
\end{tabular}

No statistical difference noted between the two groups. The main reasons for induction of labour was prolonged pregnancy, Pregnancy induced hypertension, and premature rupture of membranes.

Table 2: Details of age, height and Bishops score of the study group.

\begin{tabular}{|c|c|c|}
\hline Patient details & Group A & Group B \\
\hline $\begin{array}{l}\text { Mean age of the } \\
\text { patients }\end{array}$ & $\begin{array}{l}20 \text { years } \\
(18-33)\end{array}$ & $\begin{array}{l}\text { 21years } \\
(18-30)\end{array}$ \\
\hline $\begin{array}{l}\text { Mean height of the } \\
\text { patients }\end{array}$ & $\begin{array}{l}157 \mathrm{~cm} \\
(150-165 \mathrm{~cm})\end{array}$ & $\begin{array}{l}155 \mathrm{~cm} \\
(148-163 \mathrm{~cm})\end{array}$ \\
\hline $\begin{array}{l}\text { Mean pre-induction } \\
\text { Bishops Score }\end{array}$ & 4 & 5 \\
\hline Gestational age & $39.2 \pm 1.82$ & $40.1 \pm 1.72$ \\
\hline
\end{tabular}

With respect to patient profile that is, the mean age, height of the women and pre-induction Bishops score in Group A and B are comparable.

Table 3. Dosage of misoprostol.

\begin{tabular}{|llll|}
\hline $\begin{array}{l}\text { Number of doses } \\
\text { for successful }\end{array}$ & $2.25 \pm 0.53$ & $2.71 \pm 0.60$ & $<0.0001$ \\
outcome & $12.90 \pm 2.40$ & $15 \pm 3.75$ & $<0.001$ \\
\hline $\begin{array}{l}\text { Induction- } \\
\text { delivery interval } \\
\text { (in hours) }\end{array}$ & & & \\
\hline
\end{tabular}

Both group A and Group B had 100 women. The mean number of doses of misoprostol for induction was 
$2.25 \pm 0.53$ in the vaginal group and $2.71 \pm 0.60$ in the oral group. ( $\mathrm{P}$ value $<0.0001$ ). Vaginal route of administration was more effective when compared to oral group.

Table 4: Acceleration with oxytocin infusion.

\begin{tabular}{|llll|}
\hline Oxytocin infusion & Group A & Group B & Total \\
\hline Needed & 13 & 17 & 30 \\
\hline Not needed & 87 & 83 & 170 \\
\hline Total & 100 & 100 & 200 \\
\hline
\end{tabular}

Thirteen women in the vaginal misoprostol group needed cxytocin infusion for acceleration whereas seventeen women in the oral group needed the same. This is not statistically significant. The need for oxytocin infusion was more in women with poor Bishops score.

Table 5: Details of delivery.

\begin{tabular}{|lll|}
\hline Delivery details & Group A & Group B \\
\hline Vaginal delivery & 79 & 60 \\
\hline Outlet forceps delivery & 9 & 8 \\
\hline Caesarean section & 12 & 32 \\
\hline Total & 100 & 100 \\
\hline
\end{tabular}

The incidence of vaginal delivery was more in group A in comparison to group B.

The induction delivery interval in hours, in the group which received oral misoprostol was $15 \pm 3.55$ hours where as those women who received vaginal misoprostol needed $12.90 \pm 2.40$ hours. This implies that vaginal misoprostol led to shorter induction to delivery interval. ${ }^{7,8}$

Caesarean section rates were $12 \%$ in Group A and $32 \%$ in Group B. This indicates that vaginal administration of misoprostol is more effective in successful induction followed by vaginal delivery. The indication for caesarean section was same in both groups i.e. fetal distress, non-progress of labour and failed induction.

Table 6: Maternal side effects.

\begin{tabular}{|llll|}
\hline Complaint & Group A & Group B & Total \\
\hline Nausea & 3 & 3 & 6 \\
\hline Vomiting & 3 & 4 & 7 \\
\hline Headache & 2 & 1 & 3 \\
\hline Fever & 8 & 7 & 15 \\
\hline $\begin{array}{l}\text { Uterine hyper } \\
\text { stimulation }\end{array}$ & 7 & 4 & 11 \\
\hline Total & & & \\
\hline
\end{tabular}

The most common side effects noted are nausea, vomiting, headache fever, and uterine hyperstimulation. None of the side effects warranted stopping the drug.

The fetal outcome shows no significant differences in the two groups. ${ }^{8-10}$ The average birth weight (group A
$2900 \pm 300 \mathrm{~g}$ ) versus (Group B $2800 \pm 350 \mathrm{~g}$ ) which is again comparable.

Table 7: Fetal/neonatal complications.

\begin{tabular}{|lll|}
\hline & Group A & Group B \\
\hline Meconium stained liquor & 5 & 11 \\
\hline Meconium aspiraton & 4 & 4 \\
\hline NICU admission & 15 & 20 \\
\hline
\end{tabular}

No neonatal death was seen in either of the groups. There was no case of severe birth asphyxia in either groups. All the babies had APGAR $>7$ at 5 minutes in both the groups.

\section{DISCUSSION}

Since its first usage in 1987, misoprostol has become an important drug in induction of labour. It is well absorbed through various mucosal routes, but the most often used routes are oral and vaginal for induction of labour. Its affordability, stability and safety are well documented.

\section{Pharmacokinetics}

Women who received vaginal misoprostol had lesser gastrointestinal side effects.

Pharmacokinetic studies reveal that during vaginal administration, plasma concentration reaches peak value in about 1-2 hours and then falls slowly. ${ }^{6}$ The plasma concentration of vaginal misoprostol increases slowly and the peak concentration in plasma is found to be lower when compared to oral administration; but the overall exposure to misprostol is more when vaginal mode of administration is used.

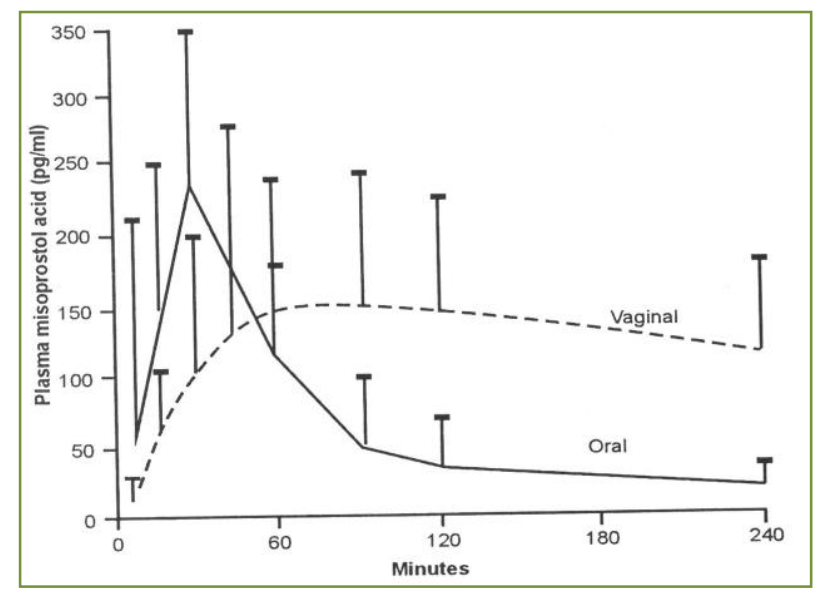

Figure 3: Plasma concentration of misoprostol following vaginal and oral route of administration.

The mean number of doses of misoprostol for induction was $2.25 \pm 0.53$ in the vaginal group and $2.71 \pm 0.60$ in the oral group ( $\mathrm{P}$ value $<0.0001$ ). The outcome of this study reveals that when used in equal dosage in similar 
schedule, vaginal route is more effective than oral administration. The induction delivery interval in hours, in the group which received oral misoprostol was $15 \pm 3.55$ hours where as those women who received vaginal misoprostol needed $12.90 \pm 2.40$ hours. This implies that vaginal misoprostol led to shorter induction to delivery interval. ${ }^{7,8}$

The numbers of doses of misoprostol for successful outcome of labour in the vaginal group i.e. $2.25 \pm 0.53$ was lesser than the dosage needed in the oral group i.e. $2.71 \pm 0.60$ ( $\mathrm{P}$ value M 0.0001) which is highly significant. The induction-delivery interval was also less in the vaginal group compared to the oral group. (12.90 \pm 2.40 hours versus $15 \pm 75$ hours). Only 13 women in the vaginal group needed acceleration with oxytocin in contrast to 17 women in the oral group. No statistically significant difference was seen in neonatal outcome in either of the groups.

Caesarean section rates were $12 \%$ in Group A and $32 \%$ in Group B. This indicates that vaginal administration of misoprostol is more effective in successful induction followed by vaginal delivery. The indication for caesarean section was same in both groups i.e. fetal distress, non-progress of labour and failed induction.

\section{CONCLUSION}

This study shows that for induction of labour, vaginal misoprostol is more effective in comparison to oral misoprostol when administered in similar dosage of 50 microgram. The vaginal route requires lesser dosage, the induction delivery interval and the incidence of failed induction is also less in this group. With respect to the neonatal outcome no significant statistical difference was noted in either of the groups.

\section{ACKNOWLEDGMENTS}

The authors are indebted to the Director Shimoga Institute of Medical Sciences and Ethical committee of the College who have given us the permission to conduct this study. We are grateful to Head of the Department and staff of Department of OBG who have supported and helped us throughout the study. Heartfelt thanks to the hospital staff in general and to the labour ward staff in particular for their co-operation during the study.
Funding: No funding sources

Conflict of interest: None declared

Ethical approval: The study was approved by the Institutional Ethics Committee

\section{REFERENCES}

1. Singh TG. Clinics in obstetrics. $1^{\text {st }}$ Ed. Jaypee Brothers Medical Publishers;2015:612.

2. Singh TG. Clinics in obstetrics. $1^{\text {st }}$ Ed. Jaypee Brothers Medical Publishers;2015:613.

3. Miriani Neto $\mathrm{C}$, Delbin $\mathrm{AL}$, Júnior V. Padräo tocográfico desencadeado pelo misoprostol. Rev Paul Med. 1988;106(4):205-8.

4. Induction of labour, ACOG Practice Bulletin No. 107. American College of Obsetericians and Gynecologists. Obstet Gynecol. 2009:114: 386-97.

5. Bartusevicius A, Barcaite E, Nadisauskiene R. Oral, Vaginal and Sublingual misoprostol for induction of labour Int J Gynecol Obstet. 2005;91(1):2-9.

6. Zieman M, Fong SK, Benowitz NL, Banskter D, Darney PD. Absorption kinetics of misoprostol with oral or vaginal administration. Obstet Gynecol. 1997;90(1):88-92.

7. Fisher SA, Mackenzie VP, Davies GA. Oral versus vaginal misoprostol for induction of labor: a doubleblind randomized controlled trial. Am J Obstet Gynecol. 2001;185(4):906-10.

8. Shetty A, Danielian P, Templeton A. A comparison of oral and vaginal misoprostol tablets in induction of labour at term. $\mathrm{Br} \mathrm{J}$ Obstet Gynecol. 2001;100:238-43.

9. How HY, Leaseburge L, Khoury JC, Siddiqi TA, Spinnato JA, Sibai BM. A Comparison of various routes and dosages of misoprostol for cervical ripening and the induction of labor. Am J Obstet Gynecol. 2001;185:911-5.

10. Jindal P, Avasthi K, Bala T. A Comparison of Vaginal misoprostol versus Foley's catheter with oxytocin for induction of labour. J Obstet Gynecol. 2006;108:1130-7.

Cite this article as: Ambika HE, Bhat S, Lepakshi BG, Savitha CS. Comparative study of efficacy and safety of vaginal misoprostol versus oral misoprostol in induction of labour when used in equal doses. Int $\mathrm{J}$ Reprod Contracept Obstet Gynecol 2017;6:3828-31. 